First Peoples Child \& Family Review

A Journal on Innovation and Best Practices in Aboriginal Child Welfare Administration,

Research, Policy \& Practice

\title{
Talking about the Aboriginal Community: Child Protection Practitioners' Views
}

\section{Christopher Walmsley}

Volume 1, Number 1, 2004

URI: https://id.erudit.org/iderudit/1069585ar

DOI: https://doi.org/10.7202/1069585ar

See table of contents

Publisher(s)

First Nations Child and Family Caring Society of Canada

\section{ISSN}

1708-489X (print)

2293-6610 (digital)

Explore this journal

Cite this article

Walmsley, C. (2004). Talking about the Aboriginal Community: Child Protection Practitioners' Views. First Peoples Child \& Family Review, 1(1), 63-71.

https://doi.org/10.7202/1069585ar
Article abstract

Child protection practitioners view Aboriginal communities as victim, adversary, participant, partner, and protector of children. These representations of communities are derived from interview data with 19 Aboriginal and non-Aboriginal child protection social workers in British Columbia, Canada. The representations of the community are informed by the practitioner's geographic relationship to the community and the length of community residency (including whether it's the practitioner's community of origin). Practitioners view communities as a victim or adversary when no relationship of trust exists with the community. Practitioners view communities having a participative or partnership role in child protection when trust has developed. When communities take full responsibility for children's welfare, practitioners view the community as the protector of children. No clear association was found between the different representations of the community and the practitioner's culture or organizational auspices. The practitioner's own vision of practice is believed to significantly influence the relationship that develops with the community.
This document is protected by copyright law. Use of the services of Érudit (including reproduction) is subject to its terms and conditions, which can be viewed online.

https://apropos.erudit.org/en/users/policy-on-use/ 


\section{Abstract}

Child protection practitioners view Aboriginal communities as victim, adversary, participant, partner, and protector of children. These representations of communities are derived from interview data with 19 Aboriginal and nonAboriginal child protection social workers in British Columbia, Canada. The representations of the community are informed by the practitioner's geographic relationship to the community and the length of community residency (including whether it's the practitioner's community of origin). Practitioners view communities as a victim or adversary when no relationship of trust exists with the community. Practitioners view communities having a participative or partnership role in child protection when trust has developed. When communities take full responsibility for children's welfare, practitioners view the community as the protector of children. No clear association was found between the different representations of the community and the practitioner's culture or organizational auspices. The practitioner's own vision of practice is believed to significantly influence the relationship that develops with the community.

\section{Talking about the Aboriginal Community: Child Protection Practitioners' Views}

\section{Christopher Walmsley}

\section{Introduction}

The community context has significant effects on children's welfare and can represent risk factors to wellbeing or contributions to resilience (Booth \& Crouter, 1999; Werna, Dzikus, Ochola, Kumarasuriyar, 1999). Child welfare theorists stress the importance of community-based intervention to effective child protection practice (Burford \& Hudson, 2000, Macdonald, 1997; Wharf, 2002). Family group conferencing, for example, involves community members in effective planning for the child's welfare (Burford \& Hudson, 2000). Social network intervention at the neighbourhood level increases social support and decreases the risk of child maltreatment (Fuchs, 1995, p. 121). Community empowerment approaches to child welfare see solutions to community problems coming from the community and not "wellmeaning outsiders" (Brown, Haddock, \& Kovach, 2002, p. 147). Community social workers, it is argued, enhance community competence and create a positive social environment (Fellin, 1995, p. 264). While theorists and researchers stress the significance of community to practice, it is unclear how child protection practitioners think about community in practice. To what extent do practitioners consider the community when practicing child protection? More particularly, when community is a minority within the dominant society, and the practitioner is a member of the dominant society how is "community" represented in the practitioner's thinking? When the practitioner is a member of the minority community is it represented differently? This article outlines five ways in which child protection practitioners think about the community in the context of their protection practice with Aboriginal children and families.

\section{Method}

\section{Participants}

The sample comprised 19 participants recruited through the researcher's contacts with British Columbia (BC) child protection social workers. The participants met the following criteria: (1) a completed bachelor or master of social work degree, (2) at least two years fulltime work experience as a child protection social worker, (3) employed by either 
The study is informed by

the social representations

perspective that argues

social representations

structure and orient

practitioners' thinking

about action, and thereby

constitute an important

conceptual guide to

practice action. the BC Ministry for Child and Family Development (MCFD) or an Aboriginal child welfare organization in British Columbia, (4) had job responsibility to assess a child's risk of harm and the authority to remove a child from the family, (5) had extensive professional contact with Aboriginal communities. Specifically, the sample included seven Aboriginal women, eight non-Aboriginal women, and four non-Aboriginal men. Practice experience ranged from 2 to 20 years. Of the 19 participants, three had MSW degrees and 16 had BSW degrees. Six were first-level supervisors and 13 were "front-line" practitioners. Seven were employed at Aboriginal child welfare organizations and 12 were employed at MCFD. The participants lived and worked in small urban centres, rural communities and reserve communities in British Columbia, Canada. Eight local offices of the BC Ministry for Child and Family Development and four Aboriginal child welfare organizations in the province were represented.

\section{Data Collection}

Semi-structured interviews were conducted at various work sites between June 1998 and October 1999, lasting 1.5 to 2 hours following an interview guide designed to explore, in part, the influence of the community context on practitioner's thinking about practice (other practice dimensions were also explored in the interview).

\section{Data Analysis}

A professional secretary transcribed the interviews and the researcher verified the accuracy of the transcription. The data were entered into the NUD*IST software program, and coded using: (1) the questions from the interview guide, and (2) naturally emerging categories from the data. Each interview was recoded a second time at an interval of 2 to 6 weeks and the new coding verified against the initial coding. Reports were printed for each code and the data analyzed for similarities, differences, variations, and negative instances. A summary of results was written for each code noting similarities and differences as well as themes and silences. The data were summarized and interpreted, and a draft of the study's findings given to each participant to review for accuracy, quality of interpretation and completeness. Participants had the opportunity to provide oral or written feedback. They were also invited to participate in two focus groups, one comprised of Aboriginal social workers and the other of nonAboriginal social workers, to discuss and validate the findings. Revisions were made to incorporate participants' feedback and the data analysis process concluded.

The study is informed by the social representations perspective that argues social representations structure and orient practitioners' thinking about action, and thereby constitute an important conceptual guide to practice action. A social representation is defined as "a system of values, ideas, and practices that establish a consensual order among phenomena" and "enable communication to take place among the members of a community by providing them with a code for social exchange" (Moscovici in Duveen and Lloyd, 1993, p. 91).

\section{Results}

\section{The Geography of Practice}

Those interviewed for this study live in a variety of community contexts ranging from isolated reserve communities to regional town centres. The context in which practice occurs for some is circumscribed within a 3 kilometre radius of the office. Others practice within a series of small communities found in an 8 hour driving radius from the office by gravel road. Some communities are accessible only by air, whereas others require a combination of air and road travel. The differing geographical relationships to practice impact the way practitioners view the "community" as 
When practitioners and community members live in distant geographical relationships to each other, a level of social distance and formality enters the practitioner-community relationship. well as the community's understanding of child protection practice.

When practitioners and community members live and work in close proximity, the possibility of reciprocity in child protection is enhanced. Informal, noncrisis oriented interactions are possible as this Aboriginal practitioner in an Aboriginal organization describes:

...we have very much an open door policy, although, you know, we try to schedule appointments and stuff, they never work, people are always popping in, and I think that's really good and people are coming in, they're asking why we're doing what we're doing and asking us to stand behind our decisions and...not only questioning how do we do the work that we do but giving direction as to where we should be going.

A MCFD practitioner in a small community confirms this sense of reciprocity:

...we even got to the point where families themselves would be phoning and identifying when they felt they needed services or when they'd need respite or they were feeling that they were slipping and they wanted to come up with a plan ahead of time and they felt comfortable enough phoning us and talking to us directly.

If the practitioner is a member of the community, the sense of reciprocity is almost taken for granted as this Aboriginal practitioner in an Aboriginal organization reports:

In the community we know everyone, we don't have to introduce ourselves. We go in, we know what the background is, we know the history...we go into the home, we know the family, we work out a plan.... With our community...everyone knows us, and they know the job we do, so the respect is there. The trust is there....

\section{The Practitioner as Outsider}

When practitioners and community members live in distant geographical relationships to each other, a level of social distance and formality enters the practitioner-community relationship. To the community, the practitioner is the distant outsider who appears in the community as the external "other" to complete an investigation and determine whether a child is in need of protection. When the practitioner "goes in" for a short period of time, the community tends to view the practitioner as a temporary visitor:

.... a lot of time you'll hear comments from the community, "Well, oh yah, here they come, flying in, flying out".

The focus of work is the completion of a task -- often the assessment of a child's safety and the negotiation of an alternate care arrangement. But when the time allotted for the community visit is $1 / 2$ to 1 day, little time remains for relationship development. The possibility of reciprocity in the community-practitioner relationship is much less when the focus of practice is investigation to determine a child's safety, and removal to ensure safety-usually outside the community.

\section{The Practitioner as Community Resident}

When a practitioner resides in the community, a different kind of child protection relationship is possible. While the practitioner knows community members and is visible in the community, the child protection possibility also contains a paradox. The practitioner's increased visibility and accompanying credibility brings decreased anonymity. There is a loss of personal privacy. The life of the practitioner is increasingly lived "in a glass bubble" or "fishbowl" and the distinction between public/professional life and a private/personal life becomes blurred. Life is lived with the community's full knowledge and this heightened visibility creates stresses and demands of its own.

Aboriginal practitioners who live and work in their communities of origin 


Within the community,
child protection is a
practice by outsiders who
investigate and remove
children when safety is at
risk. In this representation,
practitioners have minimal
relationships with the
community; the community
doesn't participate in child
protection and has no
identifiable role.

Within the community, child protection is a practice by outsiders who investigate and remove children when safety is at risk. In this representation, practitioners have minimal relationships with the community; the community protection and has no identifiable role. describe opportunities for supportive informal intervention outside the office, and the possibility of bringing a lifelong knowledge of the person to the interaction. But the lack of anonymity places demands on the practitioner for a lifestyle that conforms to community norms and is congruent with professional practice. An Aboriginal practitioner describes it this way:

...everything we do here is basically seen by the communities. We are like in a fish bowl, you know, the life style we live in and outside the office people see. It has an impact and, I think that is also why we are looking at the type of life styles people have after hours. If they continue to go and 'party hardy' with some of their clients that doesn't sit well with who we are as an agency and come Monday morning I have to deal with that family.

One MCFD practitioner in a small community describes his "glass bubble" experience in a similar way:

...you're working even when you're in the grocery store. You're working if you're walking down the street. You're perceived as working, you're known as the social worker to the town and your actions reflect on the work that you do.

The loss of anonymity in small communities creates opportunities for a greater level of reciprocity in community life as well as in the protection of children, but it brings with it a loss of privacy. It can also bring a strong sense of isolation for practitioners who are 'in but not of' the community, and can be a contributing factor to the high turnover of staff in isolated communities

In summary, the practitioner's geographic relationship to the community, and their status within the community as either a lifelong community member, an outsider, or a community resident informs the social worker's thinking about the Aboriginal community and its relationship to child protection. The balance of the article describes practitioners' ways of viewing the Aboriginal community.

\section{The Community as Victim}

Some represent the community as a victim in child protection. They see a relationship of powerless dependency to the state and view their practice reinforcing the community's victimization. They find a lack of community interest or participation in child protection decision-making, and neither community leaders nor members take identifiable responsibility for children's welfare. A high level of internal community disorganization may exist and this translates into an absence of support services and alternate caregivers in the community. One community member may use the intervention of an external child protection practitioner as a threat against another member --perhaps as an expression of lateral violence. Within the community, child protection is a practice by outsiders who investigate and remove children when safety is at risk. In this representation, practitioners have minimal relationships with the community; the community doesn't participate in child protection and has no identifiable role. The condition of victimization is re-created for the community each time a social worker parachutes into a community, makes a brief assessment, and leaves with all the children at risk. This form of practice often reactivates the image of the " $60 \mathrm{~s}$ scoop" in the minds of the community. One MCFD practitioner comments:

...you're going into these small Aboriginal communities and removing their children, you know. I don't like doing that, but you're also setting up or perpetuating something that has occurred for generations so the relationship that you're forming, well you're not forming a relationship, all you're doing is antagonizing what relationship may be there....it's just like a continuation of the 60's scoop....You'd get a call, say in a more disorganized 
With an absence of community-based resources, the child is deemed at risk, and the practitioner sees no alternative but to remove the child from the community. community...(that) a child's at risk, you go in and investigate. There would be very little involvement from community leaders, resource personnel that might be in the community such as a teacher or nurse or alcohol drug counsellor, and you'd be left to your own devices basically to plan for the child.

With an absence of community-based resources, the child is deemed at risk, and the practitioner sees no alternative but to remove the child from the community.

\section{The Community as Adversary}

Some represent communities as adversaries in child protection. The community is perceived as closed to outsiders, including the child protection practitioner, and an adversarial relationship with child protection intervention exists. Usually this is expressed as anger at the B.C. Ministry for Child and Family Development, and confrontation with its representatives. A minimal level of reciprocity with the child protection practitioner exists and there is a formal relationship with the community for the completion of investigation, removal, and alternative placement tasks. There are few opportunities to establish working relationships. When the community is represented as an adversary, the practitioner may serve as a lightening rod for the community's anger at child protection removals. An Aboriginal practitioner employed at MCFD describes walking onto a reserve in a community that wasn't her own:

There is a family that I have gone to on reserve, it's just almost the same. "You're coming here to take the kids". When I took the white social worker to the reserve...they said, "You're not allowed on the reserve". And I thought, "Holy Cow", but we were able to calm them down and let them know why we were there....

An MCFD practitioner describes her experience in the following way:

...when I worked up north, it was a clear understanding...that you did not go onto the reserve unless you were invited and when they invited us it was for a protection concern and it always ended up as a result of a removal. We weren't ever able to put in family supports or child care workers or whatever.

Sometimes, the confrontation becomes politicized as one MCFD practitioner describes:
...when we do come out there...some homes may say, "No, you're not allowed in". "You've got to go get the Chief or whatever". And then depending upon the family, if they have political pull or not it will depend upon whether or not the Chief actually supports us and helps us or if he says, "No, you can't, I'm making some phone calls". And then it goes from there. Some families it depends upon who you are on the reserves. Some of the Bands don't care at all about them, you can do whatever with them, go and investigate, but if there's some political pull, it takes a lot with the lawyers and all that to get anywhere near the children and parents.

This practitioner continues:
...in some cases they'll go up the higher ranks and then we have to bow out and it becomes a big political mess rather than just going through the investigation. They get a lot of the higher Aboriginals involved, our management gets involved and a lot times people higher up may not know the actual what's going on...it just gets stuck up in politics rather than where it should be down below.

At its more politicized levels, the adversarial confrontation involves the police and the media.

\section{The Community as Participant}

Some practitioners represent communities as a participant in the protection of children. At its most minimal level, this is expressed when community 


...because the family
relationships are so
intertwined and connected
and strong in this
community, we know that
the work that we do has a
rippling effect throughout
the community.

...because the family

relationships are so

and strong in this

community, we know that

the work that we do has a

the community. members take responsibility to report child protection concerns to an Aboriginal child welfare organization or the Ministry for Child and Family Development. One MCFD practitioner describes this occurring once trust has been established with the community:

$$
\begin{aligned}
& \text {...the calls we were receiving to } \\
& \text { investigate increased over the two } \\
& \text { years that I was there so that's also, } \\
& \text { to me, saying there is an increase in } \\
& \text { trust. }
\end{aligned}
$$

The community becomes a participant in child protection when social workers consult with the community in assessment and intervention planning. Sometimes this occurs through informal conversations with Band leaders, the Band social development worker, teachers, nurses, or daycare workers. An Aboriginal practitioner describes her approach this way:

If I was going into a community I would phone and say, "Well who do I need to speak to about this?" I want to get some information on this and I am going to be coming out there in a couple of days, who do I need to touch base with?

At other times, consultation with the community is more formal through the organization of a case conference. The community is involved in child protection, but responsibility rests largely with the formal agency, although there is the beginning of a reciprocal relationship. Reciprocity in child protection practice can be expressed through community initiative to find or create alternate care resources. One MCFD practitioner describes it this way:

...in some of the Aboriginal communities, there's a lot more use of extended family in times of crisis. There was, I mean, (a) lot of people were drinking, there was an acknowledgement that usually there was somebody who was sober enough and able enough to look out for the kids.... There was somewhere for the kids to go or some means of protecting those kids.... We involved a lot of our people in the community in what we were doing.

\section{The Community as Partner}

Practitioners represent some communities as a partner in child protection suggesting mutual responsibility for child protection, and a reciprocal relationship based on mutual respect. Child protection intervention is acknowledged to have an effect on the entire community:
...because the family relationships are so intertwined and connected and strong in this community, we know that the work that we do has a rippling effect throughout the community.

Social workers make conscious efforts to share decision-making with the community:
We were going to follow through on what we said we were going to do, that our planning involved the Bands, involved extended family, if the family wanted that to happen, and we'd involve the school in the planning. So these types of things would take place and the input was valued and it was appreciated and that if at all possible, if we had any way possible of implementing it we would do so.

Another characteristic of the partnership is that members of the community contact the agency at non-crisis times to discuss child protection issues:
We have also had teachers phone us, just to say, "You know, I think this family needs some support here, they need a visit from your office.

Sometimes children and youth contact the agency directly to make their needs known:

We have had kids come in here and say, "Mom and Dad are drinking. They are fighting. There is no food. I am scared, I don't want to go home." They are feeling safe enough to come 
Some communities have developed committee structures to enable the community to have an ongoing role in child protection. in here and tell us that and so we would say, "OK, we will help, where do you want to be?".... We had a 17 year old come in and state that, "My Mom has been drinking for the past week. She parties and stuff. I need places to go and rest where there is no alcohol and no drugs". So we say, "OK, where do you want to be?" She says, "Well I want to be out of the community...where I can get some quiet and some rest". That is what we try and give them.

When a partnership exists, the agency and community share responsibility for child protection such as the creation of new childcare resources. An Aboriginal practitioner in an Aboriginal organization describes:

...before we place children in there to ensure that they are going to be safe and taken care and not abused and used while they're in their home...we also get feedback from community members. Like we usually go through the Band social worker, and check with them or if they have... child welfare committees or social development committees, we'll ask them if they would support this home as a resource because it is going to be within their community and they will be best to know whether or not that would be a good place for the children to be in.

Some communities have developed committee structures to enable the community to have an ongoing role in child protection. One Aboriginal practitioner describes a committee and it's relationship to an Aboriginal child welfare organization:

...they have a child welfare committee...we have been meeting with them a month at a time. You know, once per month in which they reviewed all of their cases that were ongoing with us, as well as the Bands GFA to find out if there are some issues, who is doing it and what needs to be done and, you know, what recommendations could we make...
Here there is clearly a reciprocal relationship between the community and the agency to ensure the protection of children.

\section{The Community as Protector}

Some practitioners represent the community as the principal protector of children with external child protection agencies playing a minimal to non-existent role. This representation is most often expressed by Aboriginal practitioners, and may re-create earlier representations of the Aboriginal community's approach to childcare before child welfare legislation was introduced. One Aboriginal practitioner sums it up this way:

\section{...traditionally, it wasn't uncommon for other members of the community to look after your kids and basically that's all that we're doing now.}

Responsibility for children's welfare becomes a collective responsibility and community members intervene to create alternative care arrangements for children as needed. Grandparents, aunts and uncles are recognized as playing significant childcare roles. An Aboriginal participant describes it in the following way:
...long ago our community was always community orientated. We were always, you know, I guess a community. Our connections are there. We know everyone, we're related. We help out.... We always knew how to look after our children, our extended family would come in, the grandparents would come in. It always happened, I mean the community got together and said, "Hey, we have a problem here. Our aunt over here needs a break from her children. Can someone in the family take over?" That happened. We didn't need a child welfare act and all that stuff....

A non-Aboriginal MCFD practitioner confirms this by describing how a community intervenes to protect children when the parents are unable: 
Practitioners' thinking about

the community is influenced

by the community's

openness to collaboration, the availability of support services, the distance the practitioner needs to travel to reach the community, the practitioner's vision of child protection practice and the practitioner's relationship history with the community.
Some of those families...still have a far stronger traditional sense so a number of things happen when they see unseemly behaviour or inappropriate behaviour. Mom and Dad are drinking, Mom and Dad are allowing a sexual abuser in the home, they will speak to them because that's the role of the Matriarch or the Chief, is they'll have a talk with them. Ah, you are not behaving properly, you need to do this. This is your job. And if the parents don't respond, they'll take the kids and I'll hear of it later. They'll say, "Oh, by the way, we have John and Jessie's kids now, in case you are looking they're here. And they're not getting them back until they straighten out." And you know, the funny thing, John and Jessie never say boo. They don't go to court. They don't phone the cops, they don't say peep, you know, they go, "Oh, ok", and either they keep drinking or they sober up real fast, but that's a strong family doing it's traditional role, child protection.

\section{Conclusion}

This study, an interpretation of practitioners' representations of the Aboriginal community, suggests actual relationships between child protection practitioners and Aboriginal communities are informed by these representations. Practitioners' thinking about the community is influenced by the community's openness to collaboration, the availability of support services, the distance the practitioner needs to travel to reach the community, the practitioner's vision of child protection practice and the practitioner's relationship history with the community. The community is often viewed as a victim or adversary when a relationship of trust has not developed between the community and the practitioner. When there is a relationship of trust, practitioners view community participation and partnership as possible in child protection. Practitioners may view the community as the children's protector when a community takes full responsibility for children's welfare.

In this study, no clear association was found between the differing representations of the community and the practitioner's culture or organizational auspices. This suggests the ways in which practitioners see the Aboriginal community is complex and requires further research. If the practitioner is living and practicing child protection in their community of origin, the complexities of practice may not yet be adequately understood. While this study identified the loss of personal privacy, the opportunity for informal intervention, and the possibility of bringing a lifelong knowledge of the person to the work, it did not discuss the challenge of dual relationships. To what extent do practitioners' relationships with extended family members and the family's history within the community create situations of conflicting loyalty for an Aboriginal practitioner in their community of origin? At the same time, if a non-Aboriginal practitioner lives in a distant geographic relationship to an Aboriginal community, but has an approach to practice that values community participation, is a different community-practitioner relationship possible? This study was limited by a small sample, one semistructured interview for data collection, and interpretation by a non-Aboriginal researcher. Further research needs to be conducted by Aboriginal researchers focused on Aboriginal practitioners working within their community of origin to develop a fuller understanding of the ways in which child protection practitioners view the community.

An understanding of the significance of community within Aboriginal child welfare is important for all child protection practitioners. Teaching the significance of community to practice is needed to introduce social workers to different ways of protecting Aboriginal children, and to develop a commitment to the inclusion of community in practice. 


\section{First Peoples Child \& Family Review, Volume 1, Number 1, 2004}

An understanding of the significance of community within Aboriginal child welfare is important for all child protection practitioners.

\section{References}

Booth, A. \& Crouter A. (Eds.). (1999). Does it take a village: Community effects on children, adolescents, and families. Mahwah, NJ: Lawrence Erlbaum Associates.

Burford, G. \& Hudson, J. (Eds.). (2000). Family group conferencing: New directions in community-centered child and family practice. New York: Aldine De Gruyter.

Brown, L., Haddock, L., \& Kovach, M. (2002). Watching over our families and children: Lalum'utul' Smun'eem Child and Family Services. In B. Wharf (Ed.), Community work approaches to child welfare (pp. 131151). Toronto: Broadview.

Duveen, G. and Lloyd, B. (1993). An ethnographic approach to social representations. In Breakwell, G.M. and Canter, D.V. (Eds.). Empirical approaches to social representations (pp. 90-109). Oxford: Clarendon.

Farr, R. and Moscovici, S. (Eds.). (1984). Social representations. Cambridge, Paris: Cambridge University, Editions de la Maison des Sciences de l'Homme.

Fellin, P. (1995). The community and the social worker. (2nd ed.). Itasca: F.E. Peacock.

Fuchs, D. (1995). Preserving and strengthening families and protecting children: Social network intervention, a balanced approach to child maltreatment. In J. Hudson \& B. Galaway (Eds.) Child welfare in Canada: Research and policy implications (pp. 113-122). Toronto: Thompson Educational.

MacDonald, J. (1997, May). Community dimensions to child protection practice in B.C. A presentation to a research seminar held at the UBC School of Social Work.

Werna, E., Dzikus, A., Ochola, L., Kumarasuriyar, M., (1999). Implementing the Habitat agenda: Towards child-centred human settlement development in developing countries. Aldershot: Ashgate.

Wharf, B. (Ed.). (2002). Community work approaches to child welfare. Toronto: Broadview. 